\title{
Bioengineering of Genetically Encoded Gene Promoter Repressed by the Flavonoid Apigenin for Constructing Intracellular Sensor for Molecular Events
}

\author{
Nicole M. Desmet ${ }^{1,2}$, Kalyani Dhusia ${ }^{1}$, Wenjie Qi ${ }^{1}$, Andrea I. Doseff ${ }^{3,4} \mathbb{D}^{D}$, Sudin Bhattacharya ${ }^{1,4} \mathbb{D}$ \\ and Assaf A. Gilad 1,2,5,* \\ 1 Department of Biomedical Engineering, Michigan State University, East Lansing, MI 48824, USA; \\ nicole.m.desmet.gr@dartmouth.edu (N.M.D.); kalyani.dhusia@einsteinmed.org (K.D.); \\ qiwenjie@msu.edu (W.Q.); sbhattac@msu.edu (S.B.) \\ 2 Division of Synthetic Biology and Regenerative Medicine, Institute for Quantitative Health Science and \\ Engineering, Michigan State University, East Lansing, MI 48824, USA \\ 3 Department of Physiology, Michigan State University, East Lansing, MI 48824, USA; doseffan@msu.edu \\ 4 Department of Pharmacology and Toxicology, Michigan State University, East Lansing, MI 48824, USA \\ 5 Department of Radiology, Michigan State University, East Lansing, MI 48824, USA \\ * Correspondence: gilad@msu.edu
}

Citation: Desmet, N.M.; Dhusia, K.; Qi, W.; Doseff, A.I.; Bhattacharya, S.; Gilad, A.A. Bioengineering of Genetically Encoded Gene Promoter Repressed by the Flavonoid Apigenin for Constructing Intracellular Sensor for Molecular Events. Biosensors 2021, 11, 137. https://doi.org/10.3390/ bios11050137

Received: 17 February 2021

Accepted: 26 April 2021

Published: 28 April 2021

Publisher's Note: MDPI stays neutral with regard to jurisdictional claims in published maps and institutional affiliations.

Copyright: (c) 2021 by the authors. Licensee MDPI, Basel, Switzerland. This article is an open access article distributed under the terms and conditions of the Creative Commons Attribution (CC BY) license (https:// creativecommons.org/licenses/by/ $4.0 /)$.

\begin{abstract}
In recent years, Synthetic Biology has emerged as a new discipline where functions that were traditionally performed by electronic devices are replaced by "cellular devices"; genetically encoded circuits constructed of DNA that are built from biological parts (aka bio-parts). The cellular devices can be used for sensing and responding to natural and artificial signals. However, a major challenge in the field is that the crosstalk between many cellular signaling pathways use the same signaling endogenous molecules that can result in undesired activation. To overcome this problem, we utilized a specific promoter that can activate genes with a natural, non-toxic ligand at a highlyinduced transcription level with low background or undesirable off-target expression. Here we used the orphan aryl hydrocarbon receptor (AHR), a ligand-activated transcription factor that upon activation binds to specific AHR response elements (AHRE) of the Cytochrome P450, family 1, subfamily A, polypeptide 1 (CYP1A1) promoter. Flavonoids have been identified as AHR ligands. Data presented here show the successful creation of a synthetic gene "off" switch that can be monitored directly using an optical reporter gene. This is the first step towards bioengineering of a synthetic, nanoscale bio-part for constructing a sensor for molecular events.
\end{abstract}

Keywords: cytochrome P450; family 1; subfamily A; polypeptide 1 (CYP1A1); flavonoids; apigenin

\section{Introduction}

Recent innovations in Synthetic Biology, including dramatic reductions in the cost of DNA synthesis and sequencing [1,2], have opened many new possibilities for using biological material as a replacement for traditional "electronic devices". As such, biological components can be combined with electronic biosensors for miniaturing, and to improve integration with target tissue. For such integration to occur, a new set of biological parts (or "bio-parts") should be developed. These bio-parts are required to be highly specific and have the ability to communicate with electronics. The input and output is commonly achieved by light [3-7], chemicals [8,9], or electromagnetic irradiation [10-15].

The idea that genes could be activated or suppressed was first pioneered in prokaryotic cells due to their ease and simplicity, but gene switches have since been developed for eukaryotic cells as well. Gene switches are natural or synthetic systems that allow initiation, interruption, or termination of target gene expression [16]. Many of the gene switches are based on gene promoters. Promoters consist of DNA sequences usually preceding the gene open reading frame which are essential for gene regulation. There are only a 
few examples that stand out for the use of promoters in mammalian cells as switches, which are activated by metabolites [17], ions [18], optogenetics [19] or miRNA [20], but essentially the most effective gene switch is tetracycline-dependent repressor (TetR) [21] This promoter/repressor system is the most ubiquitous system that is used in mammalian cells. Mainly because it has no crosstalk with other signaling pathways it does not activate any other gene, and consequently has no cellular side effect. In this study, we sought to expand the synthetic promotor toolbox available as bio-parts for future design and construction of bio-electronic hybrid devices.

The aryl hydrocarbon receptor (AHR) is a ligand-activated transcription factor that serves as a sensor of developmental and environmental signals [22], but whose endogenous activators and their roles are poorly understood [23]. Inactivated, the AHR resides in the cytosol bound to inhibitory cofactors, including heat shock protein 90 (hsp90) and aryl hydrocarbon receptor interacting protein (AIP) (Figure 1). Upon activation by a ligand, the cytosolic AHR undergoes a conformational change that frees it from the inhibitory cofactors [24]. This allows the AHR-ligand complex to translocate into the nucleus and associate with the aryl hydrocarbon receptor nucleus translocator (ARNT) protein [25]. This complex then binds to specific DNA sequences on target genes called AHR response elements (AHRE) and is known to activate the transcription of the Cytochrome P450, family 1 , subfamily A, polypeptide 1 (CYP1A1) by binding specifically to its upstream promoter.

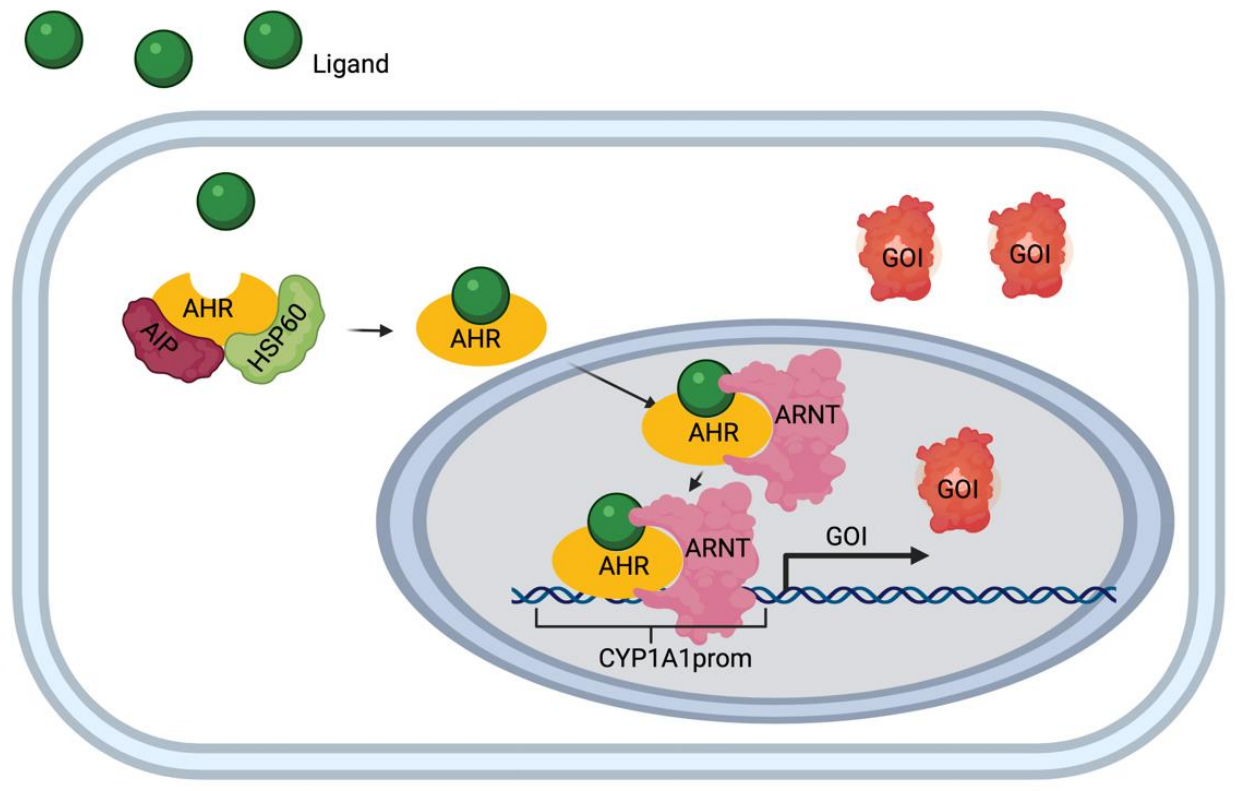

Figure 1. Aryl hydrocarbon receptor (AHR)/Cytochrome P450, family 1, subfamily A, polypeptide 1 (CYP1A1) pathway diagram. Ligand (e.g. apigenin) enters the cell and binds to the receptor complex (AHR, interacting protein (AIP) and heat shock protein 60 (hsp 60). The AHR-ligand complex translocates to the nucleus upon binding to AHR response elements (AHRE). Once in the nucleus, the complex binds to the CYP1A1 promotor (CYP1A1prom) and initiates the transcription and translation of the gene of interest (GOI).

Most known AHR ligands are toxins and xenobiotics, such as 2,3,7,8-tetrachlorodibenzoB-dioxin (TCDD) [24]. Additionally, flavonoids, one of the most abundant phytochemicals, have been identified as weak AHR ligands [26]. Flavonoids are a class of polyphenolic secondary plant metabolites broadly found in fruits and vegetables. These compounds are generally recognized as health promoting, immuno-modulators and are components of traditional medicines and commercially-available nutraceuticals [27].

This gene circuit, while complex, gives three accessible points of modification: the ligand, the receptor, and the promoter. In this study, we discussed our work on each, and how these come together to produce a sensitive synthetic gene switch which can be 
remotely suppressed, as well as future work for developing a sensitive activator. The applications of this cellular system are broad and include immune or stem cell imaging and tracking, in situ remote activation of gene expression in cells of interest as well as implementing Synthetic Biology in building bio-electronic hybrid sensors.

\section{Materials and Methods}

\subsection{Plasmid Synthesis and Construction}

A $2 \mathrm{~Kb}$ region upstream of the CYP1A1 gene is in the human genome part of the promoter region. This sequence was used as the experimental CYP1A1 promoter. To determine an optimal promoter sequence that will drive the expression of a reporter gene in response to flavonoids, a machine learning model, XGBoost [28], was trained using the AHR binding sites found in human breast cancer Michigan Cancer Foundation-7 (MCF-7) cells. The promoter region was cloned into pGlow TOPO TA expression plasmid (Invitrogen, catalog number: K483001) following the product's protocol. Additionally, the reporter gene green fluorescent protein (GFP) was replaced with mScarlet using the NEBuilder HiFi DNA Assembly kit (New England BioLabs catalog number: E5510S) to produce two different expression vectors.

\subsection{Cell Culture and Western Blot}

HeLa and HEK293FT cells were cultured in Dulbecco's modified Eagle's medium (DMEM) (GIBCO catalog number: 11965118) supplemented with 10\% $(v / v)$ fetal bovine serum (GIBCO catalog number: 16000044) and 1\% penicillin/streptomycin (GIBCO catalog number:15140122) at $37^{\circ} \mathrm{C}$ in a humidified incubator with $5 \% \mathrm{CO} 2$.

The presence of the aryl hydrocarbon receptor (AHR) was performed using Western Blot analysis using the AHR Antibody (MA1-513) from TermoFisher according to the manufacturer protocol.

\subsection{Transfection}

Cells were seeded in a 24 -well plate at a density of $10^{5}$ cells/well and given overnight to properly adhere and subsequently transfected with either the experimental plasmid (pGlowCYP1A1 $1_{\text {prom }}$ or pGlow-CYP1A1 $1_{\text {prom }}:$ mScarlet), negative control plasmid (pcDNA3.1/V5His-TOPO/lacZ), or no DNA using Lipofectamine 3000 Transfection Reagent (Invitrogen catalog number: L3000015) following the product protocol. Cells were incubated with the transfection mixture for $24 \mathrm{~h}$.

\subsection{Flavonoid Treatment}

Transfected cells were then seeded in a 96-well plate at a density of 15,000 cells/well and given overnight to properly attach to the well bottom. Quercetin was purchased from Cayman Chemical (catalog number: 10005169) and dissolved in Dimethyl sulfoxide (DMSO) to a $220 \mathrm{mM}$ stock solution (Sigma Aldrich catalog number: D8885-500G), apigenin and naringenin were purchased from Sigma and dissolved in DMSO as $20 \mathrm{mM}$ and $100 \mathrm{mM}$ stock solutions, respectively. Flavonoid stock solutions were kept at $-20{ }^{\circ} \mathrm{C}$. Flavonoids were diluted in cell media to achieve $100 \mu \mathrm{M}$ working concentration, and then each flavonoid, in addition to a $0 \mu \mathrm{M}$ control (DMSO), was added to each transfected cell group for $48 \mathrm{~h}$. This produced 12 individual experimental groups.

\subsection{Imaging}

Following incubation, cells were washed with Phosphate-buffered saline (PBS; GIBCO catalog number: 10010023) and covered with Fluorobrite DMEM (GIBCO catalog number: A1896702). Images were taken on the Keyence BZ-X800 microscope using the BZ-X GFP filter for the GFP construct or the BZ-X Tetramethylrhodamine (TRITC) filter for the mScarlet construct. 


\subsection{Quantitative Analysis}

Following imaging, quantitative analysis was done using the VictorNIVO (PerkinElmer) microplate reader. The settings of excitation: $560 \mathrm{~nm}$, emission: $593 \mathrm{~nm}$ were used.

\subsection{Structure Prediction, Docking and Validation}

The amino acid sequence of target protein $4 x+2$ named as crystal structure of the high affinity ARNT C-terminal PAS domains in complex with a tetrazole-containing antagonist was taken from the Protein Data Bank database (https:/ /www.rcsb.org/structure/4XT2, accessed on 27 April 2021) [29]. To generate a reliable 3d structure 4xt2_A was remodeled using i-tessar target-template alignments.

To improve the quality of predicted model of 4xt2_A, energy minimization was performed with the gromos 96 force field. This force field permits to evaluate the energy of the modelled structure as well as overhaul distorted geometries through energy minimization. All computations during energy minimization were done in vacuum system, without relative force fields.

To assess flavonoid binding to the AHR (PDB: 4xt2), binding sites were predicted in the 3D structure of AHR using the CASTp server [30]. The interaction energy between the AHR and the ligand was scored for evaluation using Autodock Vina Package in mgltools. Line diagrams of flavonoids in AHR binding site generated by LIGPLOT [31]. The diagrams depict the hydrogen-bond interaction patterns and hydrophobic contacts between the ligand(s) and the main-chain or side-chain elements of the protein.

\section{Results and Discussion}

A combined approach of molecular and computational biology was used to model and engineer a synthetic gene switch optimized in three ways: ligand, receptor, and promoter.

\subsection{Identifying the Optimal Promoter Sequence}

To determine an optimal promoter sequence that will drive the expression of a reporter gene in response to flavonoids, a machine learning model, XGBoost [28]. was trained on the AHR binding sites found in human breast cancer MCF-7 cells [32]. The resulting binding probabilities from 10 base pair segments containing the 'GCGTG' motif are displayed in Table 1. Screening of a $2 \mathrm{~Kb}$ promoter region upstream of the transcription start site revealed 5 locations with putative binding probability of the AHR/ARNT complex greater than 0.5 , suggesting that the complex bound to these locations would initiate transcription. This finding was validated by a computational model which shows AHR bound with ARNT form the transcription factor complex, visualized by UCSF Chimera Viewer (Figure S1). Therefore, the $2 \mathrm{~Kb}$ sequence of the promoter was determined as sufficient and was used for cloning.

\subsection{Bioengineering an Optical Reporter System}

To determine the compatibility of the gene switch with the host cells, we showed that the AHR protein is expressed in HeLa and HEK293FT cells, as confirmed by western blot analyses (Figure 2a). This step was crucial to ensuring that these cells could support this reporter system. Next, a synthetic DNA fragment encoding to the $2 \mathrm{~Kb}$ region of the human CYP1A1 promoter was cloned into the pGlow plasmid upstream of the EGFP reporter gene. Since flavonoids show autofluorescence in the green spectrum, EGFP was then replaced with a red shifted reporter, mScarlet, via Gibson assembly. The plasmid map is depicted in Figure $2 b$. 
Table 1. Ten putative AHR/aryl hydrocarbon receptor nucleus translocator (ARNT) binding sites and their corresponding binding probabilities.

\begin{tabular}{cc}
\hline \multicolumn{1}{c}{ Motif } & Binding Probability \\
\hline ACGCTGGGCGTGCAGATGC & 0.17791858 \\
\hline CCGGCTCGCGTGCGCCGGC & 0.6637833 \\
\hline CTAGCTTGCGTGCGCCGGC & 0.5893966 \\
\hline AGGCGTTGCGTGAGAAGGA & 0.82652086 \\
\hline GCGCGCGGCGTGGGGTTGG & 0.15912299 \\
\hline TAGGTCTGCGTGTGGCTTC & 0.6745489 \\
\hline TGTATTTGCGTGCCTAGCT & 0.87979823 \\
\hline CCCCCTCGCGTGACTGCGA & 0.4820609 \\
\hline GCCACAGGCGTGGACCGAA & 0.15255722 \\
\hline ATTACAGGCGTGGGCCACC & 0.2313509 \\
\hline
\end{tabular}

a
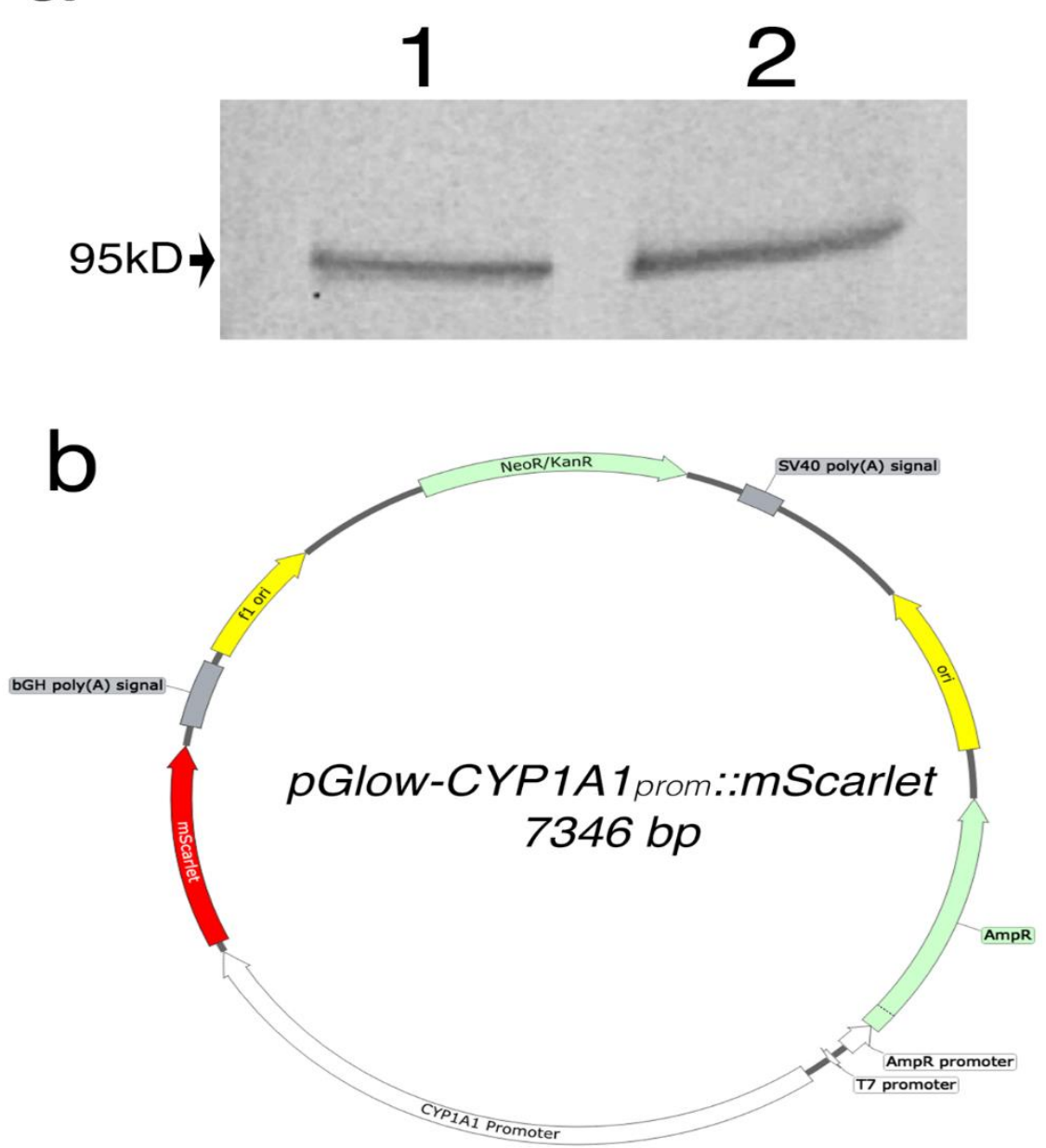

Figure 2. (a) Western blot analysis of AHR protein expression in HEK293FT (1) and HeLa (2). A band represents the AHR was observed at $95 \mathrm{kD}$ as expected. (b) Vector map of pGlow-

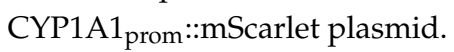




\subsection{Testing the Gene Switch Reporter System In Vivo}

To test the gene switch reporter system in vitro, HeLa cells were chosen for their stronger adherence to the plate, which was important due to the need of rigorous washes. After optimization of the timeline parameters (Supplementary material), cells were transfected with the pGlow-CYP1A $1_{\text {prom }}:: m S c a r l e t$ plasmid for $24 \mathrm{~h}$, then subsequently treated with $100 \mu \mathrm{M}$ of either quercetin, apigenin or naringenin for $48 \mathrm{hrs}$. Interestingly, the pGlow-

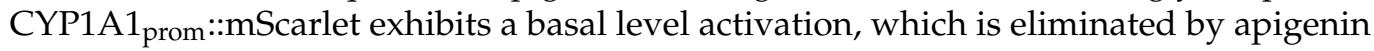
(Student's $t$-test; $p<0.01$ ). Additionally, the signal was slightly enhanced by naringenin, and unchanged by quercetin, however, this was not found to be statistically significant. The control groups transfected with either pcDNA3.1/V5-His-TOPO/lacZ or No DNA exhibit no mScarlet expression, as shown in Figure 3. These findings indicate that among the three flavonoids tested, apigenin can be used successfully as a synthetic "off"-switch of gene expression.
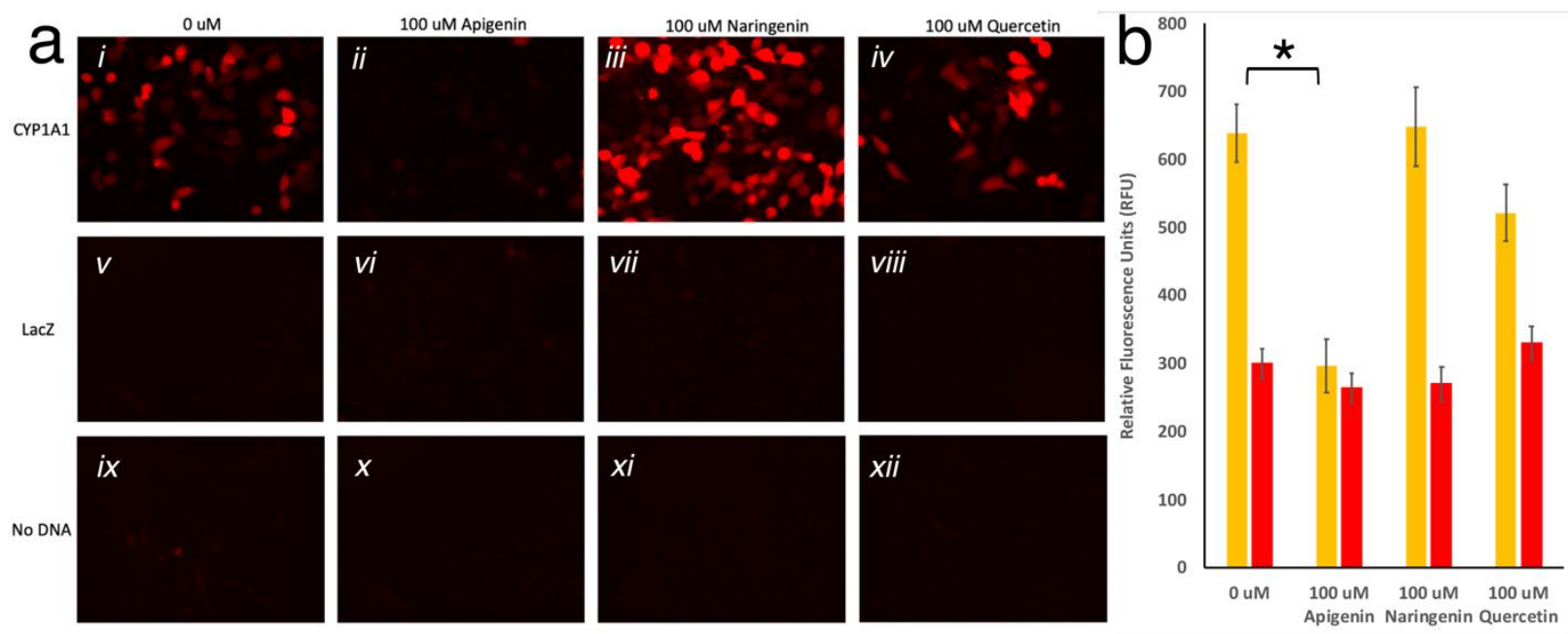

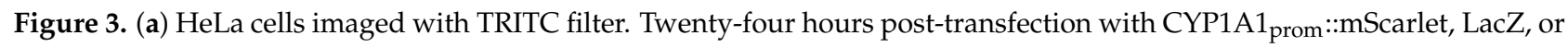
no DNA, cells were treated with $0 \mathrm{uM}(i, v, i x$ respectively), $100 \mu \mathrm{M}$ apigenin (ii, vi, $x$ respectively), $100 \mu \mathrm{M}$ naringenin (iii, vii, $x i$ respectively), or $100 \mu \mathrm{M}$ quercetin ( $i v$, viii, xii respectively) for twenty-four hours, washed, and imaged. (b) Fluorescence (Ex 560; Em 593) measured in HeLa cells transfected with CYP1A1 prom::mScarlet or No DNA, treated with $0 \mu \mathrm{M}, 100 \mu \mathrm{M}$ apigenin, $100 \mu \mathrm{M}$ naringenin, or $100 \mu \mathrm{M}$ quercetin. Each bar represents an average of $\mathrm{n}=3$. Yellow bars show significant reduction in the average $( \pm \mathrm{SD})$ fluorescence in the presence of apigenin, but not in other conditions, to the fluorescent level of untransfected cells (red bars; * represents $p<0.01$ ).

\subsection{Ligand/Receptor Binding Analysis}

To assess flavonoid binding to the AHR (PDB: 4xt2), binding sites were predicted in the 3D structure of AHR using the CASTp server, as shown in Figure 4.

The interaction energy between the AHR and the ligand was scored for evaluation using Autodock Vina Package in mgltools. Results are shown in Table 2. The 43L or racemic tetrazolo-tetrahydropyrimidines are a natural substrate that bind with lower energy score, revealing that they have higher binding affinity towards 4xt2 (AHR) than TCDD. Ligand TCDD had the lowest energy score $(-5.7 \mathrm{Kcal} / \mathrm{mol})$ after $43 \mathrm{~L}$ and apigenin which signifies that it has the highest binding affinity towards the active site of $4 x+2$. The second and third best docked molecules were naringenin and quercetin which showed high binding affinity for the 4 xt2.

The results described above revealed the ability to generate a synthetic gene switch using the CYP1A1/AHR pathway. This pathway was chosen because it is dormant in mature cells and is not activated by any known endogenous ligand, only by exogenous-natural or synthetic-compounds. Flavonoids were screened to identify strong activators and suppressors of this gene circuit to allow for sensitive control. Thus far, apigenin was found 
to be an efficient suppressor. Using computational analysis, we found potential sites on the promoter region of AHR for future improvements of this gene switch. Promoter mutants were simulated and screened for the optimal sequence which would maximize transcription factor-promoter binding. Ligand-receptor binding simulations were performed to identify key amino acids involved with binding in the ligand binding pocket of the AHR. These could be targets for protein mutagenesis to increase binding efficiency. Once all three prongs have been optimized, this fine-tuned synthetic gene switch could be utilized for vast imaging and therapeutic purposes.

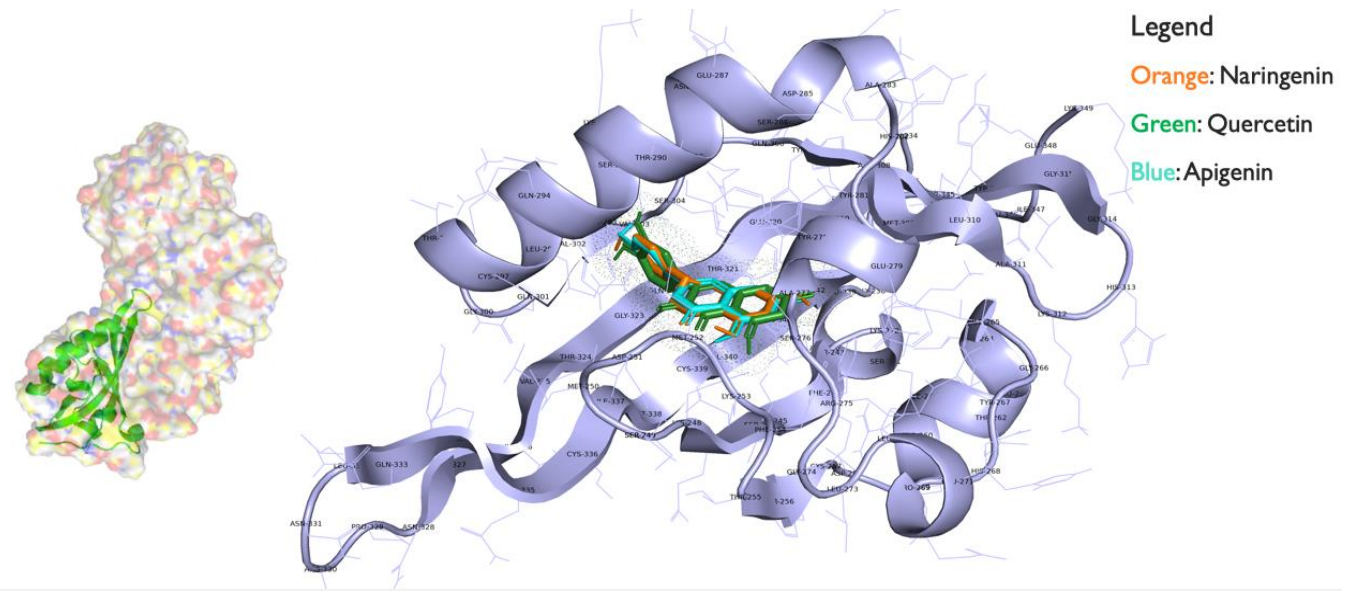

Figure 4. AHR bound with the flavonoids quercetin, naringenin, and apigenin ligands using autodock from mgltools.

Table 2. AHR ligands and their docking energy with AHR. TCDD: 2,3,7,8-tetrachlorodibenzo-B-dioxin.

\begin{tabular}{cc}
\hline Ligands & Binding Energies (Kcal/mol) \\
\hline Apigenin $5280443^{1}$ & -5.4 \\
\hline Naringenin $932^{1}$ & -5.6 \\
\hline${\text { Quercetin } 5280343^{1}}^{2}$ & -5.5 \\
\hline $43 \mathrm{~L}^{2}$ & -5.8 \\
\hline TCDD & -5.7 \\
\hline
\end{tabular}

${ }^{1}$ PubChem number. ${ }^{2}$ Inbound with protein.

While it is clear that we developed a reliable "off" system with apigenin, future optimization of the "on" system with naringenin is warranted. This would allow the sensitivity to be increased without compromising on the tightness of the "off" switch. This could be accomplished by adding elements such as enhancers, co-factors, and genetic mutations to increase ligand-receptor binding strength and duration. Another direction to explore is to develop the "on" system by optimizing for a different flavonoid, such as luteolin or quercetin, and reducing the basal level.

Here we used a concentration of $100 \mu \mathrm{M}$ of flavonoids. While $100 \mu \mathrm{M}$ is a relatively high concentration for dietary interventions and some cellular models, this concentration was selected among those found to successfully validate protein that are directly associated with apigenin in vivo [33]. Moreover, several studies have used $100 \mu \mathrm{M}$ as part of cellular platforms [34-37]. Therefore, the use of $100 \mu \mathrm{M}$ in this study is reasonable. In future studies, dose dependency experiments will be needed to optimize the system.

In this study we have used transient transfection to test the system. Transient transfections allow high expression of transgene for a relatively short time (1-3 days). However, as is evident from this study, not all of the cells are expressing the gene of interest, and there is variability in the expression levels between cells. For long term stability, viral transduction is required. This allows promoter-specific control of reporter genes [38,39]. Alternatively, 
CRISPR technologies can be used for integration of the transgene directly to the genome in a known location. This will ensure more homogenous expression.

Here, we investigated regulation of the CYP1A1 promoter by flavonoids and discovered that apigenin is a good candidate for promotor repression. Future investigations are required to elucidate the kinetics of this regulation, how long the ligand is efficient, and what the nature of the switch is. It is important to study the kinetics of this process in order to better fine-tune the system.

Our overall goal is to engineer a completely synthetic signal transduction system that will allow controlling gene expression specifically and at will, while eliminating any crosstalk with other cellular components. This is essential for developing the future generation of in vivo Synthetic Biology—hybrid electronic biosensor devices.

Supplementary Materials: The following are available online at https:/ / www.mdpi.com/article/10 .3390/bios11050137/s1, Figure S1. AHR/ARNT complex modeled by UCSF Chimera Viewer.

Author Contributions: Conceptualization, N.M.D., S.B., K.D., W.Q., A.I.D. and A.A.G.; formal analysis, N.M.D., S.B., K.D., W.Q., A.I.D. and A.A.G.; investigation, N.M.D., S.B., K.D., W.Q., A.I.D. and A.A.G.; resources, S.B., A.I.D., A.A.G. and W.Q.; data curation, N.M.D., K.D. and W.Q.; writingoriginal draft preparation, N.M.D., S.B. and A.A.G.; writing-review and editing, N.M.D., S.B., K.D., W.Q., A.I.D. and A.A.G.; visualization, N.M.D. and K.D.; supervision, A.A.G.; project administration, A.A.G.; funding acquisition, A.A.G. All authors have read and agreed to the published version of the manuscript.

Funding: This project is supported in part by the NIH grants (for A.A.G) R01 NS098231, R01 NS104306 and P41 EB024495. Michigan AgBioResearch (S.B.).

Institutional Review Board Statement: Not applicable.

Informed Consent Statement: Not applicable.

Data Availability Statement: Data are available upon reasonable request.

Acknowledgments: We are thankful to Connor J. Grady, XiaoXian, Zhang for assistance with cloning and to Rita Martin for manuscript edits.

Conflicts of Interest: The authors declare no conflict of interest.

\section{References}

1. Ruder, W.C.; Lu, T.; Collins, J.J. Synthetic biology moving into the clinic. Science 2011, 333, 1248-1252. [CrossRef] [PubMed]

2. Cameron, D.E.; Bashor, C.J.; Collins, J.J. A brief history of synthetic biology. Nat. Rev. Microbiol. 2014, nrmicro3239. [CrossRef]

3. Nussinovitch, U.; Gepstein, L. Optogenetics for suppression of cardiac electrical activity in human and rat cardiomyocyte cultures. NEUROW 2015, 2, 031204. [CrossRef] [PubMed]

4. Airan, R.D.; Li, N.; Gilad, A.A.; Pelled, G. Genetic tools to manipulate MRI contrast. NMR Biomed. 2013, 26, 803-809. [CrossRef] [PubMed]

5. Zhang, F.; Gradinaru, V.; Adamantidis, A.R.; Durand, R.; Airan, R.D.; de Lecea, L.; Deisseroth, K. Optogenetic interrogation of neural circuits: Technology for probing mammalian brain structures. Nat. Protoc. 2010, 5, 439-456. [CrossRef]

6. Motta-Mena, L.B.; Reade, A.; Mallory, M.J.; Glantz, S.; Weiner, O.D.; Lynch, K.W.; Gardner, K.H. An optogenetic gene expression system with rapid activation and deactivation kinetics. Nat. Chem. Biol. 2014, 10, 196-202. [CrossRef]

7. St-Pierre, F.; Marshall, J.D.; Yang, Y.; Gong, Y.; Schnitzer, M.J.; Lin, M.Z. High-fidelity optical reporting of neuronal electrical activity with an ultrafast fluorescent voltage sensor. Nat. Neurosci. 2014, 17, 884-889. [CrossRef]

8. Gomez, J.L.; Bonaventura, J.; Lesniak, W.; Mathews, W.B.; Sysa-Shah, P.; Rodriguez, L.A.; Ellis, R.J.; Richie, C.T.; Harvey, B.K.; Dannals, R.F.; et al. Chemogenetics revealed: DREADD occupancy and activation via converted clozapine. Science 2017, 357, 503-507. [CrossRef]

9. Wess, J.; Nakajima, K.; Jain, S. Novel designer receptors to probe GPCR signaling and physiology. Trends Pharmacol. Sci. 2013, 34, 385-392. [CrossRef] [PubMed]

10. Cywiak, C.; Ashbaugh, R.C.; Metto, A.C.; Udpa, L.; Qian, C.; Gilad, A.A.; Reimers, M.; Zhong, M.; Pelled, G. Non-invasive neuromodulation using rTMS and the electromagnetic-perceptive gene (EPG) facilitates plasticity after nerve injury. Brain Stimul. 2020, 13, 1774-1783. [CrossRef]

11. Hwang, J.; Choi, Y.; Lee, K.; Krishnan, V.; Pelled, G.; Gilad, A.A.; Choi, J. Regulation of Electromagnetic Perceptive Gene Using Ferromagnetic Particles for the External Control of Calcium Ion Transport. Biomolecules 2020, 10, 308. [CrossRef] 
12. Krishnan, V.; Park, S.A.; Shin, S.S.; Alon, L.; Tressler, C.M.; Stokes, W.; Banerjee, J.; Sorrell, M.E.; Tian, Y.; Fridman, G.Y.; et al. Wireless control of cellular function by activation of a novel protein responsive to electromagnetic fields. Sci. Rep. 2018, 8, 8764. [CrossRef]

13. Gilad, A.A.; Shapiro, M.G. Molecular Imaging in Synthetic Biology, and Synthetic Biology in Molecular Imaging. Mol. Imaging Biol. 2017. [CrossRef] [PubMed]

14. Gilad, A.A.; McMahon, M.T.; Walczak, P.; Winnard, P.T., Jr.; Raman, V.; van Laarhoven, H.W.; Skoglund, C.M.; Bulte, J.W.; van Zijl, P.C. Artificial reporter gene providing MRI contrast based on proton exchange. Nat. Biotechnol. 2007, 25, 217-219. [CrossRef] [PubMed]

15. Myklatun, A.; Lauri, A.; Eder, S.H.K.; Cappetta, M.; Shcherbakov, D.; Wurst, W.; Winklhofer, M.; Westmeyer, G.G. Author Correction: Zebrafish and medaka offer insights into the neurobehavioral correlates of vertebrate magnetoreception. Nat. Commun. 2018, 9, 2859. [CrossRef]

16. Xie, M.; Fussenegger, M. Designing cell function: Assembly of synthetic gene circuits for cell biology applications. Nat. Rev. Mol. Cell Biol. 2018, 19, 507-525. [CrossRef] [PubMed]

17. Kemmer, C.; Gitzinger, M.; Daoud-El Baba, M.; Djonov, V.; Stelling, J.; Fussenegger, M. Self-sufficient control of urate homeostasis in mice by a synthetic circuit. Nat. Biotech. 2010, 28, 355-360. [CrossRef]

18. Mesko, M.; Lebar, T.; Dekleva, P.; Jerala, R.; Bencina, M. Engineering and Rewiring of a Calcium-Dependent Signaling Pathway. ACS Synth. Biol. 2020, 9, 2055-2065. [CrossRef]

19. Scheller, L.; Strittmatter, T.; Fuchs, D.; Bojar, D.; Fussenegger, M. Generalized extracellular molecule sensor platform for programming cellular behavior. Nat. Chem. Biol. 2018. [CrossRef]

20. Bloom, R.J.; Winkler, S.M.; Smolke, C.D. A quantitative framework for the forward design of synthetic miRNA circuits. Nat. Methods 2014, 11, 1147-1153. [CrossRef] [PubMed]

21. Gossen, M.; Freundlieb, S.; Bender, G.; Muller, G.; Hillen, W.; Bujard, H. Transcriptional Activation by Tetracyclines in MammalianCells. Science 1995, 268, 1766-1769. [CrossRef] [PubMed]

22. Gu, Y.Z.; Hogenesch, J.B.; Bradfield, C.A. The PAS superfamily: Sensors of environmental and developmental signals. Annu. Rev. Pharmacol. Toxicol. 2000, 40, 519-561. [CrossRef]

23. Nguyen, L.P.; Bradfield, C.A. The search for endogenous activators of the aryl hydrocarbon receptor. Chem. Res. Toxicol. 2008, 21, 102-116. [CrossRef]

24. Beischlag, T.V.; Morales , J.L.; Hollingshead, B.D.; Perdew, G.H. The aryl hydrocarbon receptor complex and the control of gene expression. Crit. Rev. Eukaryot. Gene Expr. 2008, 18, 207-250. [CrossRef] [PubMed]

25. Puga, A.; Ma, C.; Marlowe, J.L. The aryl hydrocarbon receptor cross-talks with multiple signal transduction pathways. Biochem. Pharmacol. 2009, 77, 713-722. [CrossRef]

26. Jin, U.H.; Park, H.; Li, X.; Davidson, L.A.; Allred, C.; Patil, B.; Jayaprakasha, G.; Orr, A.A.; Mao, L.; Chapkin, R.S.; et al. Structure-Dependent Modulation of Aryl Hydrocarbon Receptor-Mediated Activities by Flavonoids. Toxicol. Sci. 2018, 164, 205-217. [CrossRef]

27. Panche, A.N.; Diwan, A.D.; Chandra, S.R. Flavonoids: An overview. J. Nutr. Sci. 2016, 5, e47. [CrossRef] [PubMed]

28. Chen, T.; Guestrin, C. XGBoost: A Scalable Tree Boosting System. In Proceedings of the 22nd ACM SIGKDD International Conference on Knowledge Discovery and Data Mining, San Francisco, CA, USA, 31-17 August 2016. [CrossRef]

29. Scheuermann, T.H.; Sleet, C.E.; Bayeh, L.; Shokri, C.; Wang, H.; Caldwell, C.G.; Longgood, J.; MacMillan, J.B.; Bruick, R.K.; Gardner, K.H.; et al. Isoform-Selective and Stereoselective Inhibition of Hypoxia Inducible Factor-2. J. Med. Chem. 2015, 58, 5930-5941. [CrossRef]

30. Tian, W.; Chen , C.; Lei, X.; Zhao, J.; Liang, J. CASTp 3.0: Computed atlas of surface topography of proteins. Nucleic Acids Res. 2018, 46, W363-W367. [CrossRef]

31. Laskowski, R.A.; Swindells, M.B. LigPlot+: Multiple ligand-protein interaction diagrams for drug discovery. J. Chem. Inf. Model. 2011, 51, 2778-2786. [CrossRef] [PubMed]

32. Yang, S.Y.; Ahmed, S.; Satheesh, S.V.; Matthews, J. Genome-wide mapping and analysis of aryl hydrocarbon receptor (AHR)and aryl hydrocarbon receptor repressor (AHRR)-binding sites in human breast cancer cells. Arch. Toxicol. 2018, 92, 225-240. [CrossRef]

33. Arango, D.; Morohashi, K.; Yilmaz, A.; Kuramochi, K.; Parihar, A.; Brahimaj, B.; Grotewold, E.; Doseff, A.I. Molecular basis for the action of a dietary flavonoid revealed by the comprehensive identification of apigenin human targets. Proc. Natl. Acad. Sci. USA 2013, 110, E2153-E2162. [CrossRef]

34. Subhasitanont, P.; Chokchaichamnankit, D.; Chiablaem, K.; Keeratichamroen, S.; Ngiwsara, L.; Paricharttanakul, N.M.; Lirdprapamongkol, K.; Weeraphan, C.; Svasti, J.; Srisomsap, C. Apigenin inhibits growth and induces apoptosis in human cholangiocarcinoma cells. Oncol. Lett. 2017, 14, 4361-4371. [CrossRef]

35. Woo, J.S.; Choo, G.S.; Yoo, E.S.; Kim, S.H.; Lee, J.H.; Han, S.H.; Kim, H.J.; Jung, S.H.; Park, Y.S.; Kim, B.S.; et al. Apigenin induces apoptosis by regulating Akt and MAPK pathways in human melanoma cell A375SM. Mol. Med. Rep. 2020, 22, 4877-4889. [CrossRef] [PubMed]

36. Vargo, M.A.; Voss, O.H.; Poustka, F.; Cardounel, A.J.; Grotewold, E.; Doseff, A.I. Apigenin-induced-apoptosis is mediated by the activation of PKCdelta and caspases in leukemia cells. Biochem. Pharmacol. 2006, 72, 681-692. [CrossRef] [PubMed] 
37. Masuelli, L.; Benvenuto, M.; Mattera, R.; Di Stefano, E.; Zago, E.; Taffera, G.; Tresoldi, I.; Giganti, M.G.; Frajese, G.V.; Berardi, G.; et al. In Vitro and In Vivo Anti-tumoral Effects of the Flavonoid Apigenin in Malignant Mesothelioma. Front. Pharmacol. 2017, 8 , 373. [CrossRef] [PubMed]

38. Alon, A.; Kraitchman, D.L.; Schär, M.; Cortez, A.; Yadav, N.; Krimins, R.; Johnston, P.V.; McMahon, M.T.; van Zijl, P.C.M.; Nimmagadda, S.; et al. Molecular imaging of CXCL12 promoter-driven HSV1-TK reporter gene expression. Biotechnol. Bioprocess Eng. 2018, 23, 208-217. [CrossRef]

39. Jouroukhin, Y.; Nonyane, B.A.; Gilad, A.A.; Pelled, G. Molecular Neuroimaging of Post-Injury Plasticity. J. Mol. Neurosci. 2014. [CrossRef] [PubMed] 